\title{
Os Custos da Qualidade e a Certificação ISO 9000: Um Estudo com Dados em Painel de Companhias Abertas Brasileiras
}

Francisco Carlos Tadeu Starke Rodrigues

Mestrado em Administração de Empresas pela Universidade Presbiteriana Mackenzie Professor da Universidade Municipal de São Caetano do Sul - USCS Rua Alto Pimenta, 2. Luz. São Paulo/SP. CEP: 01106-060 E-mail: franciscostarke@starkonsult.com.br

Laércio Baptista da Silva Doutorado em Controladoria e Contabilidade pela Universidade de São Paulo - USP Professora da Universidade Municipal de São Caetano do Sul - USCS Av. Goiás, 3.400. Barcelona, São Caetano do Sul/SP. CEP: 09550-051

E-mail: lasilva@imes.edu.br

Wilson Toshiro Nakamura Doutorado em Administração pela Faculdade de Economia, Administração e Contabilidade da USP Professora da Universidade Presbiteriana Mackenzie Rua da Consolação, $8962^{\circ}$ andar sala 216. Consolação. São Paulo/SP. CEP:

05303-110

E-mail:wtnakamura@uol.com.br

Diógenes Manoel Leiva Martin

Doutorado em Administração pela Fundação Getúlio Vargas - FGV

Professora na Universidade Presbiteriana Mackenzie

Rua da Consolação, $8962^{\circ}$ andar sala 216. Consolação. São Paulo/SP. CEP:

05303-110

E-mail: diomartin@mackenzie.com.br

\section{RESUMO}

Apesar do tema custos da qualidade continuar presente nas discussões acadêmicas, percebe-se pouca utilização prática de seus conceitos. Pesquisadores têm alertado para a baixa adesão de sua real implantação nas empresas. Alternativas, portanto, devem surgir para que uma empresa possa mensurar se seus esforços produzem desempenho superior para todas as suas partes interessadas. Propõe-se com este estudo a substituição das propostas tradicionais de mensurar os custos da qualidade - distantes da prática contábil clássica - pela avaliação de um conjunto de indicadores que meçam e monitorem a satisfação das partes interessadas em uma organização. Uma dessas ferramentas é a implantação da ISO 9000. Essa norma estabelece que uma organização deva monitorar informações relacionadas à percepção do cliente quanto ao atendimento de seus requisitos. Uma empresa, ao se certificar, produz melhores resultados, já que investe em melhoria contínua. A proposta deste estudo é apresentar resultados financeiros alcançados por companhias abertas brasileiras certificadas pela ISO 9000, evidenciando que elas se utilizam dos mecanismos gerenciais propostos pela norma para alcançar melhores resultados. Ao estudar 44 companhias abertas brasileiras certificadas, por 
meio de dados em painel estático no período de 1995 a 2006, percebeu-se que houve contribuição estatística significativa da certificação para a diminuição dos custos de produção e para o aumento do giro operacional dos ativos.

Palavras-chave: ISO 9000. Custos da Qualidade. Produtividade. Giro dos Ativos. Dados em Painel.

\title{
Quality Costs and ISO 9000 Certification: A Panel Data Research with Brazilian Publicly Traded Companies
}

\begin{abstract}
Despite of quality costs theme remains involved in academic discussions, little practical use of its concepts is realized. Researchers have warned about the low commitment of their actual implementation on companies. Alternatives, therefore, must come to allow a firm can measure if its efforts produce superior performance to all its stakeholders. In this study, it is proposed a trade-off of traditional ways to measure the costs of quality - away from classical accounting practices - for an evaluation of a set of indicators that measure and monitor the satisfaction of the stakeholders in a company. One of those tools is the implementation of ISO 9000. This standard establishes that a company must monitor information related to the perception of the client regarding the accomplishment of its requirements. One company, when it is certified, produces better results, since it invests in continuous improvement. The purpose of this study is to report financial results achieved by brazilian publicly traded companies certified by ISO 9000, showing that they use the mechanisms proposed by the management standard to achieve better results. Researching 44 brazilian companies ISO 9000 certified with a static panel data from 1995 to 2006, one can verify there was statistically significant contribution of the certification to reduce the production costs and to increase the operational turnover of the assets.
\end{abstract}

Key Words: ISO 9000. Quality Costs. Productivity. Assets Turnover. Panel Data.

\section{INTRODUÇÃO}

Custos representam um sacrifício de recursos (Maher, 2001). Como os recursos são finitos, escassos, muitas vezes raros e por que não, de difícil imitação, devem ser muito bem geridos. Para isso, é preciso conhecê-los, mensurá-los e controlá-los. Sower et al. (2007) afirmam que registrar as atividades de um sistema da qualidade e sua eficiência em termos financeiros tornou-se uma importante abordagem evolutiva para ligar a melhoria contínua de um sistema da qualidade com o desempenho financeiro de uma empresa. Afinal, os custos totais da qualidade têm 
sido estimados ao longo do tempo por vários pesquisadores. Enquanto Feigenbaum (2001) afirma que $10 \%$ das vendas se destinam aos custos da qualidade, Crosby (1984) reforça que para as companhias americanas esse percentual se situa entre $20 \%$ e $35 \%$.

Crosby (1979) afirma que a "qualidade não custa dinheiro. Embora não seja um dom, é gratuita. Custa dinheiro as coisas desprovidas de qualidade - tudo o que envolve a não execução correta de um trabalho. A qualidade não só é gratuita, como realmente lucrativa".

Na década de 1980 a qualidade foi ganhando terreno junto a presidentes e diretores executivos das empresas americanas; esse fenômeno pode ser explicado pela associação da qualidade com a lucratividade e pelo fato de ela ser definida de acordo com a visão e as expectativas dos consumidores e clientes. Processos indenizatórios em função da má qualidade de produtos e serviços também começaram a abalar os modelos de gestão: de 1974 a 1981, as ações judiciais aumentavam a uma taxa média anual de 28\% (Garvin, 1992). Até 1978, agências americanas reguladoras de tráfego nas estradas, proteção ambiental e segurança de produtos de consumo já haviam retirado vinte e nove milhões de unidades de vários produtos do mercado devido a necessidades de correção de riscos potenciais para a segurança dos consumidores (Garvin, 1992).

Esse fenômeno provocou uma série de reações por parte dos governos federal e de vários estados americanos. Dentre elas, a aprovação das "leis dos limões" (Garvin, 1992), aplicáveis aos automóveis com defeitos repetitivos; os proprietários desses bens com qualidade duvidosa poderiam receber um novo bem equivalente ou, simplesmente, a devolução do valor pago. Cada processo desses podia valer milhões de dólares. Corriam risco a reputação da empresa, sua participação de mercado e sua rentabilidade.

Já ao final dos anos 1990, McNair (2007) afirma que houve uma explosão de ferramentas de gestão de custos, algumas novas e outras que foram redescobertas. Entretanto, Viger e Anandarajan (1999) encontraram apenas a metade das empresas por eles pesquisadas valendo-se do cálculo dos custos da qualidade, mas puderam confirmar que gestores que possuem acesso a custos da qualidade tomam 
melhores decisões do que aqueles que não os têm. Sower et al. (2007) consideram que os custos da qualidade, por si só, não incrementam a qualidade; eles fornecem dados de entrada e de saída para os sistemas da qualidade que são, estes sim, responsáveis pela melhoria da qualidade. Goulden e Rawlins (1995) sugerem que seja colocada maior ênfase nos custos de cada processo, mais do que arbitrariamente em um sistema de custos da qualidade no modelo: prevenção avaliação - falhas (P-A-F).

É preciso, portanto, haver outras alternativas direta ou indiretamente ligadas à gestão dos custos da qualidade. Uma delas é a série de normas ISO 9000 . Os impactos da implantação da ISO 9000 nas receitas e nos custos têm sido amplamente estudados (Jacobson e Aaker, 1987; Szymanski et al., 1993; Philips et al., 1983; Rust et al., 1985), em 1987, Jacobson e Aaker conseguiram encontrar relação positiva entre qualidade do produto e retorno sobre o investimento, fatia de mercado e preço. Flynn et al. (1995) constataram que melhores controles de processos levam a menos retrabalhos e, portanto, diminuição dos custos da qualidade.

A ISO 9001:2000 considera que "para uma organização funcionar de maneira eficaz, ela tem que identificar e gerenciar diversas atividades interligadas". A isso se pode chamar de abordagem de processos. Quando utilizada em um sistema de gestão da qualidade, permite a "obtenção de resultados de desempenho e eficácia de processo e a melhoria contínua de processos baseados em medições objetivas" (ISO 9001:2000). A ISO 9004:2000 é uma norma que fornece orientação complementar à adoção da ISO 9001:2000 (ISO 9004:2000). Em seu item 8.2.1.1, estabelece que "convém que a Alta Direção assegure que métodos eficazes e eficientes sejam utilizados para identificar áreas para melhoria de desempenho do sistema de gestão da qualidade. Exemplos incluem as medições financeiras" (ISO 9004:2000).

Gerir a qualidade nada mais é do que ter mecanismos que: (1) possibilitem produzir produtos adequados ao uso; (2) satisfaçam aos seus consumidores; (3) permitam melhoria contínua de sua qualidade; (4) permitam reduzir os custos, por meio de ações preventivas que, por sua vez, (5) promovam a devida rentabilidade 
para quem produz essa qualidade. Rodrigues (2007) comprovou haver relação direta e significativa da certificação ISO 9000 com o melhor desempenho financeiro das companhias abertas brasileiras. Estudando 207 companhias durante os anos de 1995 a 2006, confirmou haver contribuição da certificação ISO 9000 com melhores retornos sobre ativos, vendas e patrimônio líquido, além de menores custos diretos de produção e melhor utilização dos ativos.

Desta forma, propõe-se com este estudo a substituição das propostas tradicionais de mensurar os custos da qualidade - distantes da prática contábil clássica, que está fortemente presente nas companhias abertas - pela avaliação de um conjunto de indicadores que meçam e monitorem a satisfação das partes interessadas em uma organização. Como o foco principal das normas da série ISO 9000 é orientar para se obter a melhoria contínua, melhor que medir os custos da qualidade no modelo P-A-F, é acompanhar os indicadores de eficácia e eficiência de um sistema certificado de gestão da qualidade.

\section{FUNDAMENTAÇÃO TEÓRICA}

A qualidade tem sido um dos temas sobre os quais mais se têm escrito mundo afora. Os temas abordados sob o "guarda-chuva" da Qualidade são inúmeros: Qualidade Total, Kanban, Just in Time, Custos da Qualidade, Gerenciamento pelas Diretrizes, Certificação, Acreditação, Foco no Cliente, Liderança, Motivação, Gestão de Pessoas, Balanced Scorecard, Benchmarking, Seis Sigma, entre outros. Do ponto de vista acadêmico, a produção sobre custos da qualidade parece estar estagnada. Dentro do tema "Custos da Qualidade", disponibilizado nos congressos brasileiros de custos ( $A B C, 2008)$, a produção tem sido modesta; de um pico de 9 artigos sobre o tema em 2004 e 2005, apenas cinco artigos foram apresentados no último congresso.

Nunca a produção acadêmica difundida nos congressos brasileiros de custos apresentou dois dígitos. A realidade é que o tema tem tido pouca repercussão na vida contábil-econômico-financeira cotidiana das empresas brasileiras. Acredita-se que as companhias encontraram - na prática - alternativas para as propostas 
relacionadas ao tratamento dos custos da qualidade. A proposta deste estudo é apresentar resultados financeiros alcançados por companhias abertas brasileiras certificadas pela ISO 9000, evidenciando que elas se utilizam dos mecanismos gerenciais propostos pela norma para alcançar melhores resultados.

\subsection{Os custos da Qualidade}

Crosby (1979) criou um modelo próprio para a sua visão de que "qualidade é um investimento". Para ele, qualidade é conformidade com requisitos. Os custos da qualidade são dados pelo preço da conformidade e o preço da não-conformidade. Entretanto, cálculos dos custos da qualidade não são presentes nem mesmo nas empresas ganhadoras do Malcolm Baldrige National Quality Award (Baatz, 1992 apud Schiffauerova e Thomson, 2005). Schiffauerova e Thomson (2005) confirmam que a utilização dos custos da qualidade não é um conceito largamente utilizado e que as companhias raramente têm uma idéia realista do quanto de suas receitas estão sendo perdidas por conta da baixa qualidade. Schiffauerova e Thomson (2005) atestam ainda que, dentre as companhias que calculam os custos da qualidade, a maioria o faz de acordo com a metodologia P-A-F proposta por Feigenbaum.

Passa a ser vantajoso para uma companhia melhorar a qualidade de seus produtos enquanto decrescem os custos da qualidade relacionados com operações que não agregam valor (Wang et al., 2007). Apesar de não haver uma definição amplamente aceita para o que sejam custos da qualidade (Machowski e Dale, 1998), adotar-se-ão: (1) os custos incorridos no projeto, implementação, operação e manutenção de um sistema de gestão da qualidade, (2) os custos dos recursos comprometidos com a melhoria contínua, (3) os custos das falhas de sistemas, produtos e serviços e (4) todos os demais custos e atividades não agregadoras de valor requeridas para produzir um produto ou serviço de qualidade (Dale e Plunkett, 1995 in Schiffauerova e Thomson, 2005).

Feigenbaum (1991, p. 109) sustenta que, no passado, se acreditava que para obter melhor qualidade, eram requeridos maiores custos; ao contrário, qualidade insatisfatória significa utilização insatisfatória dos recursos, perdas de material, de 
trabalho, de tempo, retrabalhos e, principalmente, má utilização da capacidade e do potencial das pessoas. Isso tudo significa maiores custos.

Portanto, qualidade satisfatória significa melhor utilização dos recursos sempre e, consequentemente, menores custos. Desta forma, os custos da qualidade estabelecem a economia dos sistemas da qualidade (Feigenbaum, 1991, p. 110), podendo se tornar um elemento central para a determinação do retorno sobre o investimento (Feigenbaum, 1991, p. 134): custos formam a base para análise de investimentos em programas da qualidade, avaliando-os com base em melhoria dos lucros da organização.

Analisando o atributo Qualidade como sendo a conformidade com as especificações, Forker et al. (1996) constataram que a qualidade tinha significativa relação com crescimento das vendas e com o retorno auferido com esse crescimento. Esses dois trabalhos atestaram que uma melhor conformidade dos produtos pode reduzir custos e, por consequência, a qualidade se torna mais atrativa e retentora de clientes (Heras et al., 2002).

Em 1997, Flynn et al. apontaram que, atingindo melhores índices de conformidade com as especificações e produzindo-se menores custos de retrabalho, ter-se-á um efeito direto na vantagem competitiva, ao mesmo tempo em que a percepção da gerência quanto à qualidade dos produtos e dos serviços aos clientes teria um impacto ainda maior.

\subsection{A Gestão da Qualidade pela ISO 9000}

Schiffauerova e Thomson (2005) apontam que as empresas adaptam o modelo P-A-F às suas necessidades e culturas, criando diferentes subcategorias e, sobretudo, definindo os diversos custos de maneiras diferentes. Mensurar os custos da qualidade deveria ser parte de qualquer programa de gestão da qualidade (Schiffauerova e Thomson, 2005). Entretanto, os sistemas normativos existentes hoje no Brasil - ISO 9000, Acreditação ONA, Prêmio Nacional da Qualidade e outros - não prescrevem os custos da qualidade como item obrigatório a ser implantado. Trata-se de um típico tema que é de adoção voluntária e que não pode ser compulsório na gestão de cada empresa. 
Nos trabalhos de Merino (1988) e Mandel (1972), pode-se ainda ver que as percepções eram distantes dos dias atuais: enquanto o primeiro afirma que os sistemas contábeis existentes não conseguem gerar relatórios direcionados para as medidas da qualidade, o segundo afirma que eles não produzem dados relacionados adequados à qualidade.

A certificação cria oportunidades para reduzir custos de transação e custos de procura por fornecedores. Tirole (1990, p. 106, 110-114) atestou que a padronização de práticas de compra permite reduzir os custos de fornecimento e mitigar custos de transação pelo fato de reduzir a assimetria de informações entre comprador e vendedor. Isso pressupõe que empresas fornecedoras certificadas pela ISO 9000 permitiriam aos compradores de seus produtos menores custos diretos de produção, menores custos em ter que adotar multi- critérios para cada fornecedor e menores custos de contratação (Anderson et al., 1999).

A norma ISO 9000 se baseia em princípios da gestão da qualidade, os quais podem ser utilizados pelos altos gestores como uma estrutura que direciona as empresas na busca do desempenho superior. Vários são os benefícios que podem advir da prática cotidiana desses princípios da norma ISO 9000. Entre eles, destacam-se aqueles que se relacionam diretamente com a gestão dos custos da qualidade (Roth, 1998, p. 44; Szyszka, 2002, p. 31-32):

Aumento de receitas e de fatias de mercado que podem ser obtidas por meio de respostas flexíveis e rápidas às oportunidades de mercado;

a) Aumento da eficácia no uso dos recursos da organização para ampliar a satisfação dos clientes;

b) Menores custos e menores ciclos de tempo por meio do uso efetivo dos recursos;

c) Foco em recursos, métodos e materiais que permitam melhoria das atividades- chave da empresa;

d) Otimização de custos e recursos e Balanceamento correto entre os ganhos em curto e longo prazos.

O "fazer certo da primeira vez" fica fortemente associado com uma melhor 
gestão dos fluxos dos processos, enquanto que o diferencial da qualidade está associado com melhor gestão de processos e controle de qualidade (Heras et al., 2002). Ambos são premissas e princípios da prática de gestão pregada pela ISO 9000. Um efetivo sistema de gestão da qualidade certificado de acordo com a ISO 9000 terá compulsoriamente o controle de processos como uma premissa-chave.

Operar uma empresa de acordo com o modelo de gestão por processos pode ainda contribuir para reduzir o tempo de desenvolvimento de novos produtos, os problemas de início de produção e os custos em geral (Dimara et al., 2004), assim como melhorar a eficiência dos processos internos (Santos e Escanciano, 2002). Anderson et al. (1999) apontam ainda como motivadores importantes para a busca da certificação ISO 9000 (1) a redução de custos com consequente melhoria da qualidade do produto; (2) a diminuição dos custos de transacionar com diversos clientes; (3) a oportunidade de melhorias internas nos processos de gestão das empresas; além (4) do maior envolvimento dos funcionários.

Quanto aos benefícios advindos com a certificação ISO 9000, Rodrigues (1996 in Roth, 1998, p. 31) aponta como sendo o principal, trabalhar com ênfase na prevenção. Marshall et al. (2006, p. 77-78) apresentam como principais benefícios para as empresas, entre outros, a redução de não conformidades, a eliminação do retrabalho e do custo com garantia e reposição, o aumento da competitividade, a melhoria da imagem e da reputação, o aumento da participação no mercado e o melhor desempenho organizacional.

Por outro lado, existem também evidências que comprovam haver relação entre a certificação ISO 9000 e o melhor desempenho financeiro das empresas. Pesquisadores de diversas nacionalidades (Rodrigues, 2007; Terlaak e King, 2006; Corbett et al., 2005; Anderson et al., 1999) estudaram, utilizando-se de diferentes métodos quantitativos, diversas possibilidades de relacionar certificação com desempenho, tendo encontrado resultados positivos que apoiam as hipóteses de haver correlação entre essas variáveis.

Hoje o Brasil é o primeiro país em certificações em sua "região ISO", que inclui a América Central e a do Sul, com 37,9\% das empresas certificadas na região (ISO, 2007). A ISO 9001:2000 é o padrão normativo mais utilizado no país e, 
segundo a ABNT (2007), ao final de 2005, havia 8.533 empresas brasileiras certificadas. Como a ISO 9000 é uma norma de gestão de um sistema amplo da qualidade, é necessário que uma documentação apropriada e uma padronização de procedimentos, rotinas e instruções - as práticas em geral - sejam elaboradas por uma empresa que busque se certificar a partir do cumprimento de suas exigências. Desta forma, a ISO 9000 seria, portanto uma proxy para uma uniformidade de produtos e serviços e para a conformidade com as especificações (Anderson et al., 1999).

A norma ISO 9000 parece, portanto, possuir uma cadeia lógica de abordagem: "melhoria de processos - menores custos da qualidade - incremento do foco no cliente", que resulta em benefícios financeiros. Se uma companhia consegue se certificar - e se recertificar periodicamente - pela ISO 9000 e suas várias versões ao longo do tempo, por meio de auditorias independentes de terceira parte (muitas vezes com auditores diferentes), poder-se- inferir que seu sistema de gestão da qualidade amadurece com o tempo. Há uma correlação entre a maturidade de um sistema da qualidade e a redistribuição dos custos da qualidade (Sower et al., 2007), a saber, migrando dos custos da não qualidade relacionados a falhas para os custos de prevenção e avaliação. Uma companhia certificada de acordo com a ISO 9000 demonstra bons resultados e tendências sustentáveis de melhoria, o que Sower et al. (2007) apontam como grau de maturidade 4 (em um total de 5).

\section{DESENVOLVIMENTO DAS HIPÓTESES}

A qualidade como um investimento (Crosby, 1979, p. 15) permitiria considerála como um projeto com valor presente líqüido (VPL) positivo. Segundo Feigenbaum (1991, p. 24), programas de qualidade total são uma das maiores oportunidades de "retorno sobre o investimento" para a gestão dos negócios. Qualidade e rentabilidade tornam-se sinônimos quando os conceitos da Qualidade são difundidos por toda a empresa (Gabor, 1990, p. 8). Han et al. (2007) concluem que os esforços para a certificação ISO 9000 aumentam a competitividade; e que a competitividade aumenta o desempenho das empresas, especificamente o lucro e o marketshare. 
Isso se deve, especificamente, pelo aumento da qualidade, diminuição dos custos e obtenção de maior flexibilidade operacional.

O objetivo principal, ao se adotar a ISO 9000, é melhorar o desempenho organizacional, por meio da melhor utilização de seus recursos e processos, gerando assim melhores produtos e serviços percebidos pelos clientes.

O ponto de partida para a formulação das hipóteses a serem testadas é que a adoção da certificação ISO 9000 melhora o desempenho financeiro e que essa melhoria é contínua ao longo do tempo e das versões da norma ISO 9000. A implementação da ISO 9000 obriga a empresa e seus funcionários a trabalharem mais disciplinadamente. É necessário possuir procedimentos que garantam que a qualidade seja medida e corrigida, quando necessário. A prevenção de defeitos passa a ser empregada, o que resulta em diminuição de custos operacionais. Ao se documentar as práticas, a obsolescência é identificada, tornando o conhecimento mais explícito para a empresa, o que aumenta o moral dos funcionários, que deverão produzir mais e melhor. Com o moral e a produtividade aumentados, espera-se que os custos de se produzir diminuam, justificando a adoção da certificação ISO 9000. Há evidências de que os custos de falhas diminuem em uma companhia na medida em que seu sistema de gestão da qualidade amadurece (Sower et al., 2007). Surge a primeira hipótese:

Hipótese 1: Não existe aumento significativo na produtividade, medida pelo Índice Custo de Produção / Vendas (CPRtoVEND), das companhias abertas certificadas ISO 9000.

Além disso, a certificação poderia auxiliar a reduzir a pressão por preços menores: a receita de vendas subiria nesse caso. Para se determinar se o crescimento nas vendas reflete o crescimento da empresa ou um aumento na rotatividade dos ativos, considerou-se o Índice Vendas / Ativos (VENDtoAT_TOT). Todo e qualquer esforço para melhorar a qualidade deve considerar os custos para se atingir a qualidade desejada. É preciso atender aos requisitos e anseios dos clientes e consumidores, mas dentro de uma perspectiva de custos menores. Schiffauerova e Thomson (2005) acreditam que isso somente acontece reduzindo-se 
Os Custos da Qualidade e a Certificação ISO 9000: Um Estudo com Dados em Painel de

Companhias Abertas Brasileiras

Francisco Carlos Tadeu Starke Rodrigues, Laércio Baptista da Silva, Wilson Toshiro Nakamura, Diógenes Manoel Leiva Martin

os custos necessários para atingir a qualidade; mantendo-se os níveis de ativos, pode-se utilizá-los de maneira mais eficiente, promovendo mais vendas. Companhias com sistemas de gestão mais maduros reportam que suas vendas estão aumentando (Sower et al., 2007). Além disso, uma companhia precisa estar comprometida em produzir a um custo continuamente menor para aumentar sua fatia de mercado (Omachonu et al., 2004). Surge a segunda hipótese:

Hipótese 2: Não existe aumento significativo no giro do ativo total, dado pelo índice Vendas / Ativos (VENDtoAT_TOT), das companhias abertas certificadas ISO 9000.

\subsection{As variáveis e sua Operacionalização}

A variável independente adotada foi a certificação ISO 9000, denominada CERT_ISO, que poderá adotar valor 0 para as companhias abertas não certificadas ou para os períodos em que não possuíam a certificação ISO 9000, 1 para a obtenção da certificação ISO 9000 na versão 1987 ou 1994 e 2 para a obtenção da certificação ISO 9000 na versão 2000.

Quadro 1 - As variáveis empregadas nos modelos de regressão

\begin{tabular}{|c|c|c|}
\hline Variável & Descrição & Tipo \\
\hline CPRtoVEND & Índice Custo de Produção sobre o Total das Vendas & Financeira/Dependente \\
\hline VENDtoAT_TOT & Índice Vendas sobre o Ativo Total & Financeira/Dependente \\
\hline CERT-ISO & Certificação da companhia pela ISO 9001 & $\begin{array}{c}\text { Não Financeira/Não } \\
\text { Independente }\end{array}$ \\
\hline RISCO & Risco Operacional & Financeira/Controle \\
\hline LUCRAT & Lucratividade medida pela Margem Líquida & Financeira/Controle \\
\hline ENDIV & Endividamento & Financeira/Controle \\
\hline TAM_EMP & Tamanho das Companhias Abertas Certificadas & Fesquisadas \\
\hline
\end{tabular}

Fonte: Elaborado pelos autores.

A variável risco operacional (RISCO) é medida pelo desvio-padrão amostral do retorno sobre os ativos ao longo do período. A variável lucratividade (LUCRAT) é medida pela margem líquida, dada pela razão entre lucro operacional líquido e 
Os Custos da Qualidade e a Certificação ISO 9000: Um Estudo com Dados em Painel de

Companhias Abertas Brasileiras

Francisco Carlos Tadeu Starke Rodrigues, Laércio Baptista da Silva, Wilson Toshiro Nakamura, Diógenes Manoel Leiva Martin

receita líquida vezes

100. O endividamento (ENDIV) é dado pela razão entre dívidas de longo prazo e o total do patrimônio líquido vezes 100. Por último, a variável tamanho das companhias abertas (TAM_EMP), medida pelo logaritmo dos ativos totais. O Quadro 1 apresenta o conjunto das variáveis escolhidas para o estudo.

\subsection{População, Amostra e Conjuntos da Dados}

A vantagem de se utilizar os valores de mercado para mensurar o impacto da qualidade é poder desenvolver um estudo financeiro empírico financeiramente mais robusto (Nicolau e Sellers, 2002). Este estudo compreende o período de janeiro de 1995 a dezembro de 2006 e se baseia em três grandes grupos de dados. Primeiramente, foi utilizado o banco de dados da Comissão de Valores Mobiliários (CVM), disponível gratuitamente por acesso ao seu site www.cvm.gov.br, no qual foram identificadas todas as companhias abertas com registro atual válido ou que tenham fechado seu capital em algum ano do período sob análise. O segundo passo foi identificar as companhias que possuem ou possuíam a certificação ISO 9000 em algum momento do período 1995 a 2006, pelo banco de dados do Comitê Brasileiro da Qualidade (CB-25) da Associação Brasileira de Normas Técnicas (ABNT). A seguir, foi utilizado o banco de dados da Economática; das companhias abertas selecionadas a partir do banco de dados da CVM, restaram 44 companhias abertas certificadas ISO 9000 com dados disponíveis para todos os anos do período estudado.

Companhias podem ter múltiplas certificações, mesmo dentro de uma mesma planta física, ao passo que o desempenho financeiro é medido e acompanhado no nível corporativo. Não há modo de mensurar o desempenho financeiro de uma determinada parte da companhia que seja apenas ela certificada. Assim, focou-se na primeira certificação de uma filial ou planta de uma companhia aberta, pois os efeitos de uma certificação começariam a aparecer nas demais unidades ao longo do tempo (Docking e Dowen, 1999; Simmons e White, 1999; Corbett et al., 2005).

Das 44 companhias abertas certificadas que participam da amostra, obtevese a seguinte estratificação: (1) $2,3 \%$ pertencem ao setor primário, $79,6 \%$ ao 
secundário e 18,1\% ao terciário; (2) 13,6\% das companhias possuem controle acionário estrangeiro, 4,6\% controle estatal brasileiro e $81,8 \%$ controle nacional privado; (3) 36 delas (81,8\%) se certificaram pela primeira vez pela versão 1987 ou 1994 da ISO 9000 e 8 (18,2\%) se certificaram inicialmente na versão ISO 9001:2000; (4) 27 delas $(61,4 \%)$ já estavam certificadas antes do primeiro ano do período sob análise, ou seja, antes de 1995. Foram excluídas da amostra final todas as instituições financeiras, distribuidoras de valores, de previdência privada, participação e assemelhadas. Empresas que tiveram abertura de seu capital nos anos de 2005 e 2006 ou se certificaram pela primeira vez a partir do ano de 2005 também foram excluídas. Isso também tornou a pesquisa ainda mais conservadora.

\section{METODOLOGIA DE PESQUISA}

O modelo de regressão com dados em painel estático foi o escolhido para o estudo. Foram escolhidas apenas as companhias que possuíam os dados econômico-financeiros e de mercado para todos os anos do período analisado. Obteve-se assim um painel balanceado, no qual o número de observações não difere entre as companhias participantes da amostra. Adotou-se o software Gretl em sua versão 1.6 .5 e o seguinte modelo de painel estático:

$$
\boldsymbol{Y}_{i t}=\underset{0}{\beta}+\underset{j}{\beta} \boldsymbol{x}+\mu_{i t}+\alpha_{i}
$$

$\mathrm{Na}$ equação acima, $\beta$ representa o intercepto, os demais $\beta j$ representam os coeficientes de cada variável regressora, $i$ representa a i-ésima unidade de corte transversal (as companhias abertas), $t$ representa o t-ésimo período de tempo, representa 0 termo de erro e, finalmente, $\mu_{i t} \circ$ termo de erro aleatório próprio de cada unidade de corte transversal. Enquanto o modelo de efeitos fixos considera que o intercepto do modelo poderá diferir entre os indivíduos (as companhias) para considerar o fato de que cada companhia pode ter características especiais, o modelo de efeitos aleatórios propõe que o intercepto de um indivíduo (a companhia aberta) seria uma extração aleatória de uma população muito maior e com valor 
médio constante (Wooldridge, 2006). Três categorias de modelos econométricos de regressão foram empregadas: o agrupamento de dados de corte com mínimos quadrados ordinários (MQO agrupado), os efeitos fixos (EF) e os efeitos aleatórios (EA). Os modelos estáticos de dados em painel são aqueles que consideram as variáveis independentes (os regressores) estritamente exógenas, ou seja, não admitindo defasagens das variáveis dependentes (Richieri, 2007).

Existem três hipóteses principais a serem testadas para se decidir qual dos três modelos seguir. Utiliza-se os testes F (Fischer), Breusch-Pagan (BP) e Hausman para aceitar ou rejeitar as hipóteses nulas relacionadas, respectivamente, com: (1) a existência ou não de um único intercepto das unidades de corte transversal; (2) a variância ser zero; e (3) os estimadores serem consistentes pelos Mínimos Quadrados Generalizados (MQG).

A escolha entre os modelos MQO agrupado e EF depende da eficiência relativa dos estimadores, ou seja, da existência de correlação serial nos erros idiossincráticos $\mu_{i t}$ (Wooldridge, 2006). Ao se ter os erros $\mu_{i t}$ serialmente não correlacionados, o modelo EF se torna mais eficiente que o agrupamento. Caso os $\mu_{i t}$ sigam um passeio aleatório, ou seja, existe uma correlação serial muito forte e positiva, a diferença dos $\mu_{i t}\left(\Delta \mu_{i t}\right)$ será serialmente correlacionada, concluindo-se pelo MQO agrupado como o mais adequado (Wooldridge, 2006). Greene (2000) propõe a utilização de um teste $F$ para avaliar a hipótese nula de que todas as unidades seccionais possuem o mesmo intercepto. Caso o valor $p$ obtido no teste $F$ seja baixo, rejeita-se a hipótese de que o modelo MQO agrupado seja o mais adequado, validando-se a hipótese alternativa da existência de efeitos fixos (EF).

Da mesma maneira, o processo de comparação entre os modelos MQO agrupado e EA pode ser feito por meio do teste Multiplicador de Lagrange (LM) modificado pela proposição de Breusch e Pagan (BP). Esse teste assume que os erros são distribuídos normalmente. Realiza-se o teste BP estabelecendo-se a hipótese nula de que a variância do intercepto seja igual a zero. Caso o valor $p$ do teste BP seja muito baixo, contraria-se a hipótese nula de que o modelo MQO agrupado seja o mais adequado; se valida, por conseguinte, a hipótese alternativa de que o modelo EA é o mais adequado. 
Os Custos da Qualidade e a Certificação ISO 9000: Um Estudo com Dados em Painel de

Companhias Abertas Brasileiras

Francisco Carlos Tadeu Starke Rodrigues, Laércio Baptista da Silva, Wilson Toshiro Nakamura, Diógenes Manoel Leiva Martin

A escolha entre EF e EA pressupõe haver uma provável correlação entre os componentes de erro individual ou específico ao corte transversal e os regressores. Se a pressuposição é de que ambos não estejam correlacionados, então o modelo de efeitos aleatórios é adequado; se ambos forem correlacionados, então o modelo de efeitos fixos é o mais indicado. Para facilitar a escolha entre EF e EA, utiliza-se o teste de Hausman para se analisar se não há diferença substancial entre os estimadores obtidos pelo modelo EA e os obtidos pelo modelo EF. Caso o valor $p$ obtido no teste de Hausman seja baixo, rejeita-se a hipótese de que o modelo EA seja consistente, atestando a existência de efeitos fixos.

\section{RESULTADOS}

O Quadro 2 apresenta as estatísticas básicas da amostra de 44 companhias que compõem o painel balanceado utilizado nas regressões. O total de observações foi de 528, que pode ser considerada uma amostra grande. Em todas as regressões propostas foram realizados os testes necessários, como previsto na literatura (Wooldridge, 2006, p. 245-256).

Quadro 2 - Estatísticas descritivas das variáveis

\begin{tabular}{|c|c|c|c|c|c|c|c|}
\hline Variáveis & $\mathbf{N}$ & Média & $\begin{array}{c}\text { Desvio } \\
\text { Padrão }\end{array}$ & Mediana & Mínimo & Máximo & $\begin{array}{c}\text { Coeficiente } \\
\text { de } \\
\text { Variação }\end{array}$ \\
\hline CPRtoVEND & 528 & $70,655 \mathrm{E}+01$ & $1,2866 \mathrm{E}+01$ & $7,1993 \mathrm{E}+01$ & 0,0000 & $1,1039 \mathrm{E}+02$ & 0,182098 \\
\hline VENDtoAT_TOT & 528 & 92,2734 & 82,6697 & 75,1507 & 0,0000 & 703,443 & 0,895921 \\
\hline CERT_ISO & 528 & 1,14962 & 0,690378 & 1,0000 & 0,0000 & 2,0000 & 0,600527 \\
\hline RISCO & 528 & 5,95630 & 5,38498 & 4,63288 & 0,0000 & 36,4312 & 0,904081 \\
\hline LUCRAT & 528 & 4,28067 & 42,59720 & 4,71278 & $-135,9040$ & 902,9260 & 9,9511060 \\
\hline ENDIV & 528 & 68,55370 & 327,59000 & 50,71290 & $-5429,050$ & 2353,690 & 4,778590 \\
\hline TAM_EMP & 528 & 14,31150 & 1,76606 & 14,24050 & 0,0000 & 19,1881 & 0,123402 \\
\hline
\end{tabular}

Fonte: Elaborado pelos autores

Ao analisar os dados, verifica-se o seguinte comportamento: o índice de custos diretos de produção sobre as vendas (CPRtoVEND) teve mediana de $71,9926 \%$ e o índice das vendas sobre o total dos ativos (VENDtoAT_TOT) uma 
mediana de 75,1507\%. O desvio padrão amostral (RISCO) apresentou mediana de $4,63288 \%$, enquanto a razão entre lucro operacional líquido e receita líquida (LUCRAT) teve mediana de 4,71278\%. A mediana do endividamento (ENDIV) foi de $50,71290 \%$ e o tamanho das companhias abertas (TAM_EMP) teve mediana de 14,2405 .

A multicolinearidade entre as variáveis foi investigada por meio dos fatores de inflação das variâncias (FIV). Os valores ficaram entre o mínimo de 1,017 e o máximo de 1,121, validando os modelos de regressão. Não foram identificadas correlações altas dignas de cuidados, como pode ser visto no Quadro 3. Percebemse níveis de correlação satisfatórios, o que sugere não haver qualquer viés de especificação do modelo formulado, não sendo necessária a exclusão de qualquer variável. Validou-se o uso de todas as variáveis propostas nos modelos de regressão. Note-se que a variável independente CERT_ISO possui coeficientes de correlação negativos com CPRtoVEND, RISCO e ENDIV: isso permitiria inferir que a certificação pela ISO 9000 deve contribuir positivamente com a diminuição: (1) dos custos de se produzir; (2) do risco; e (3) do endividamento. Da mesma forma, contribuiria com o aumento do giro operacional dos ativos, da lucratividade e do tamanho dos ativos.

Quadro 3 - Análise de Correlação entre as Variáveis

\begin{tabular}{|c|c|c|c|c|c|c|c|}
\hline Variáveis & $\begin{array}{c}\text { CP Rto } \\
\text { VEND }\end{array}$ & $\begin{array}{c}\text { VENDtoAT } \\
\text { TOT }\end{array}$ & CERT_ISO & RISCO & LUCRAT & ENDIV & TAM_EMP \\
\hline CPRtoVEND & 1,00000 & & & & & & \\
\hline VENDtoAT_TOT & 0,36520 & 1,00000 & & & & & \\
\hline CERT_ISO & $-0,10230$ & 0,06700 & 1,00000 & & & & \\
\hline RISCO & 0,11890 & $-0,08580$ & $-0,25220$ & 1,00000 & & & \\
\hline LUCRAT & $-0,17390$ & $-0,04400$ & 0,01370 & $-0,12270$ & 1,00000 & & \\
\hline ENDIV & $-0,08930$ & $-0,07970$ & $-0,00710$ & 0,08790 & $-0,01010$ & 1,00000 & \\
\hline TAM_EMP & $-0,17150$ & $-0,16930$ & 0,14970 & $-0,17660$ & 0,05730 & 0,16500 & 1,00000 \\
\hline
\end{tabular}

Fonte: elaborado pelos autores

A presença de heterocedasticidade foi identificada em cada uma das regressões, por meio do teste de White, sendo corrigida pela utilização dos erros- 
Os Custos da Qualidade e a Certificação ISO 9000: Um Estudo com Dados em Painel de

Companhias Abertas Brasileiras

Francisco Carlos Tadeu Starke Rodrigues, Laércio Baptista da Silva, Wilson Toshiro Nakamura, Diógenes Manoel Leiva Martin

padrão robustos a cada regressão. O software Gretl possui todas as ferramentas adequadas aos cálculos dos erros padrão robustos, de forma a eliminar a heterocedasticidade e a autocorrelação. Foram realizadas regressões para as 3 variáveis dependentes. Para a produtividade (medida por CPRtoVEND), os efeitos fixos (EF) surgiram como a melhor alternativa. Já para o giro dos ativos (medido por VENDtoAT_TOT), os efeitos aleatórios (EA) são a melhor alternativa.

\subsection{A Produtividade, medida pela variável CPRtoVEND}

A tabela 1 apresenta os resultados das regressões. O melhor modelo, definido a partir dos testes F, BP e Hausman, foi o de efeitos fixos. Comprova-se essa escolha também pelos critérios de Akaike e Schwarz. Todos os coeficientes CERT_ISO surgiram como negativos, apontando para uma contribuição positiva da certificação. Nos EF, CERT_ISO apresentou-se negativa $(-3,15706)$ e significativa a $1 \%$, mostrando a sua contribuição na redução dos custos.

Tabela 1 - Resultados para a variável Custos de Produção sobre o Total das Vendas (CPRtoVEND)

\begin{tabular}{|c|c|c|c|c|c|c|}
\hline \multirow[b]{3}{*}{$\mathbf{N}$} & \multicolumn{6}{|c|}{ Modelos } \\
\hline & \multicolumn{2}{|c|}{ MQO Agrupado } & \multicolumn{2}{|c|}{ Efeitos Fixos } & \multicolumn{2}{|c|}{ Efeitos Aleatórios } \\
\hline & 52 & & & 28 & & 28 \\
\hline Variáveis & Coeficiente & Valor $p$ & Coeficiente & Valor $p$ & Coeficiente & Valor $p$ \\
\hline CERT_ISO & $-1,20282$ & 0,42481 & $-3,15706$ & $0,00010^{\star \star *}$ & $-2,99348$ & $<0,00001^{* \star *}$ \\
\hline RISCO & 0,160651 & 0,28511 & $-0,138576$ & 0,46593 & $-0,0859538$ & 0,37373 \\
\hline LUCRAT & $-0,0477865$ & 0,28362 & $-0,0221353$ & 0,30745 & $-0,0859538$ & $0,00145^{\star \star \star}$ \\
\hline ENDIV & $-0,00298729$ & 0,27898 & $-0,000158781$ & 0,85633 & $-0,000264384$ & 0,80037 \\
\hline TAM_EMP & $-0,934893$ & 0,55549 & 2,80632 & $<0,00001^{* * *}$ & \begin{tabular}{|l|}
2,31401 \\
\end{tabular} & $<0,00001^{\star \star *}$ \\
\hline CONSTANTE & 84,8697 & $0,00037^{*}$ & - & & 41,6113 & $<0,00001^{* * *}$ \\
\hline RS Ajustado & 0,0620154 & & 0,730475 & & - & \\
\hline $\mathrm{F}$ & 7,96859 & & 30,756 & & - & \\
\hline Akaike (AIC) & 4168,21 & & 3550,37 & & 4290,92 & \\
\hline Schwarz (BIC) & 4193,83 & & 3759,56 & & 4316,54 & \\
\hline Teste F $(43,479)$ & 31,1077 & valor $p$ & 5,67E-112 & Efeitos Fixos & * Significati & ivo a $10 \%$ \\
\hline Teste Breusch-Pagan & 1062,78 & Valor $p$ & 4,06E-233 & Ef. Aleatórios & ** Significa & ativo a $5 \%$ \\
\hline Teste Hausman & 57,4475 & Valor $p$ & $4,09 \mathrm{E}-11$ & Efeitos Fixos & *** Significa & ativo a $1 \%$ \\
\hline
\end{tabular}

Fonte: elaborada por autores 
Os Custos da Qualidade e a Certificação ISO 9000: Um Estudo com Dados em Painel de

Companhias Abertas Brasileiras

Francisco Carlos Tadeu Starke Rodrigues, Laércio Baptista da Silva, Wilson Toshiro Nakamura, Diógenes Manoel Leiva Martin

Os coeficientes de TAM_EMP apresentaram valores $p$ significativos a $1 \%$ para os modelos EF e EA, demonstrando a existência de uma relação positiva, ceteris paribus, entre o nível de ativos totais e a capacidade de reduzir custos diretos de produção. Com base nos resultados encontrados, pode-se afirmar que a certificação ISO 9000 diminuiu os custos de se produzir em relação ao volume de vendas. Portanto, rejeita-se a hipótese 1.

\subsection{O Giro do Ativo Total, medido pela variável VENDtoAT_TOT}

A Tabela 2 apresenta os efeitos aleatórios como os melhores resultados das regressões. Os critérios Akaike e Schwarz, entretanto, permitiriam dizer que também os efeitos fixos devem ser considerados, já que neles foram encontrados os menores valores. Os coeficientes CERT_ISO são todos positivos, apontando que o índice VENDtoAT_TOT aumenta com a certificação ISO 9000. A certificação contribui para o aumento das vendas com o mesmo nível de ativos. Para o modelo 3 , efeitos aleatórios, o coeficiente CERT_ISO apresentou-se positivo $(20,373)$ e significativo a $1 \%$.

Tabela 2 - Resultados para a variável Vendas sobre Total dos Ativos (VENDtoAT_TOT)

\begin{tabular}{|c|c|c|c|c|c|c|}
\hline & & & \multicolumn{2}{|c|}{ Modelos } & & \\
\hline & \multicolumn{2}{|c|}{ MQO Agrupado } & \multicolumn{2}{|c|}{ Efeitos Fixos } & \multicolumn{2}{|c|}{ Efeitos Aleatórios } \\
\hline $\mathbf{N}$ & \multicolumn{2}{|c|}{528} & \multicolumn{2}{|c|}{528} & \multicolumn{2}{|c|}{528} \\
\hline Variáveis & Coeficiente & Valor $\mathbf{p}$ & Coeficiente & Valor $p$ & Coeficiente & Valor $p$ \\
\hline CERT_ISO & 8,31694 & 0,38802 & 20,607 & $0,00135^{\star * *}$ & 20,373 & $<0,00001^{* * *}$ \\
\hline RISCO & $-1,59653$ & 0,30439 & 0,0209979 & 0,96601 & $-0,011805$ & 0,97648 \\
\hline LUCRAT & $-0,0918448$ & $0,05420^{*}$ & 0,000142799 & 0,99646 & $-0,00129472$ & 0,96568 \\
\hline ENDIV & $-0,00994439$ & 0,13005 & $-0,00407803$ & 0,1482 & $-0,004119621$ & 0,32204 \\
\hline TAM_EMP & $-8,83956$ & 0,11906 & 2,33044 & 0,22615 & 1,92726 & 0,13681 \\
\hline CONSTANTE & 219,803 & $0,02022^{*}$ & - & - & 41,6338 & $0,06155^{\star}$ \\
\hline RS Ajustado & 0,0416798 & & 0,888232 & & - & \\
\hline $\mathrm{F}$ & 5,58412 & & 88,2525 & & - & \\
\hline Akaike (AIC) & 6143,97 & & 5050,04 & & 6182,55 & \\
\hline Schwarz (BIC) & 6169,59 & & 5259,22 & & 6208,17 & \\
\hline Teste F $(43,479)$ & 92,9471 & valor $p$ & $4,72976 \mathrm{E}-204$ & Efeitos Fixos & \multicolumn{2}{|c|}{ * Significativo a $10 \%$} \\
\hline Teste Breusch-Pagan & 2113,91 & Valor $p$ & 0 & Ef. Aleatórios & \multirow{2}{*}{\multicolumn{2}{|c|}{$\begin{array}{l}* * \text { Significativo a } 5 \% \\
* * * \text { Significativo a } 1 \%\end{array}$}} \\
\hline Teste Hausman & 2,70486 & Valor $p$ & 0,745375 & Ef. Aleatórios & & \\
\hline
\end{tabular}

Fonte: elaborado pelos autores 
Os sinais que se esperava encontrar para os coeficientes das demais variáveis efetivamente ocorreram, com exceção da variável LUCRAT no modelo MQO agrupado, que apresentou sinal negativo, contradizendo as expectativas iniciais. As variáveis RISCO e ENDIV (embora não estatisticamente significativas) apresentaram os sinais que se esperava: negativos. Rejeita-se, portanto, a hipótese 2 e se aceita a hipótese alternativa de que existe uma relação direta e positiva entre CERT_ISO e VENDtoAT_TOT.

\section{CONCLUSÃO}

A utilização dos custos da qualidade não é um conceito largamente utilizado pelas companhias. Essas mesmas companhias raramente têm uma ideia realista do quanto de suas receitas estão sendo perdidas por conta da baixa qualidade. Um programa baseado nos critérios da qualidade pode ser considerado como uma das maiores oportunidades para retorno de investimento na gestão dos negócios, já que qualidade satisfatória de um produto ou serviço anda "de mãos dadas" com o custo satisfatório desse mesmo produto ou serviço. Qualidade insatisfatória significa utilização insatisfatória dos recursos, perdas de material, de trabalho, de tempo, retrabalhos e, principalmente, má utilização da capacidade e do potencial das pessoas. Isso tudo significa maiores custos.

Este trabalho propôs a substituição das propostas tradicionais de mensurar os custos da qualidade - distantes da prática contábil clássica, que está fortemente presente nas companhias abertas - por uma avaliação de um conjunto de indicadores que meçam e monitorem a satisfação das partes interessadas em uma organização de acordo com a ISO 9000. Já que o objetivo da norma é orientar para se obter a melhoria contínua, melhor que medir os custos da qualidade no modelo P. A-F, é acompanhar os indicadores de eficácia e eficiência de um sistema certificado de gestão da qualidade.

Quanto aos benefícios advindos com a certificação ISO 9000, fica evidenciada a ênfase na prevenção. Outros benefícios comprovados empiricamente 
por diversos pesquisadores se referem à redução de não conformidades, a eliminação do retrabalho e do custo com garantia e reposição, o aumento da competitividade, a melhoria da imagem e da reputação, o aumento da participação no mercado e o melhor desempenho organizacional.

Por meio de um estudo em painel estático com dados de 12 anos de 44 companhias abertas brasileiras certificadas ISO 9000, pode-se comprovar a contribuição direta e significativa da certificação ISO 9000 para a melhoria da produtividade e para o maior giro dos ativos. Acompanhar, medir e controlar esses indicadores de eficiência e de eficácia pode suplantar uma dificuldade prática na adoção do modelo P-A-F pelas companhias no Brasil.

\section{REFERÊNCIAS}

Associação Brasileira De Custos (ABC). Disponível em: http://www.abc.org.br. Acesso em 08/jul/2008.

Associação Brasileira de Normas Técnicas (ABNT). Disponível em: http://www.abnt.org.br. Acesso em 19/mar/2007.

ANDERSON, S. W.; DALY, J. D. e JOHNSON, M. F. (1999). Why Firms Seek ISO 9000 Certification: Regulatory Compliance or Competitive Advantage? Production and Operations Management, 8(1):28-43.

Associação Brasileira De Normas Técnicas (ABNT). (2000). NBR ISO 9001:2000: Sistemas de Gestão da Qualidade - Requisitos. Rio de Janeiro.

Associação Brasileira De Normas Técnicas (ABNT). (2000). NBR ISO 9004:2000: Sistemas de Gestão da Qualidade - Diretrizes para melhorias do desempenho. Rio de Janeiro.

BAATZ, E. B. (1992). What is Return on Quality, and why you should care? Electronic News, October: 60-66. CHASE, N. 1998. Accounting for Quality: Counting Costs, Reaping Rewards". Quality, 37(10):38-42.

CHAUVEL, A. M. e ANDRE, Y. A. (1985). Quality Costs: better prevent than cure. In: J. CAMPANELLA (edit.). Quality Costs: Ideas and Applications. Milwaukee: ASQC Quality Press: p. 26-34.

CORBETT, C. J.; MONTES-SANCHO, M. J. e KIRSCH, D. A. (2005). The Financial Impact of ISO 9000 Certification in the United States: An Empirical Analysis. 
Management Science, 51(7):1046-1059. CROSBY, P.B. 1979. Quality is Free. 1a. ed. New York: McGraw-Hill.

DALE, B. G. e PLUNKETT, J. J. (1995). Quality Costing. (2 ed.). London: Chapman and Hall. DAMODARAN, A. 2004. Finanças Corporativas. (2 ed.). Porto Alegre: Artmed.

DIMARA, E.; SKURAS, D.; TSEKOURAS, K. e GOUTSOS, S. (2004). Strategic Orientation and Financial Performance of Firms Implementing ISO 9000. International Journal of Quality \& Reliability Management, 21(1):72-89.

DOCKING, D. S. e DOWEN, R. J. (1999). Market Interpretations of ISO 9000 Registration. The Journal of Financial Research, XXII (2):147-160.

FEIGENBAUM, A. V. (1991). Total Quality Control. (3 ed.), rev. Singapura: McGrawHill Company.

. (2001). How to manage for quality in today's economy. Quality Progress, May: 2627.

FLYNN, B. B.; SCHROEDER, R. G. e SAKAKIBARA, S. (1995). The Impact of Quality Management Practices on Performance and Competitive Advantage. Decision Sciences, 26(5):659-692.

FLYNN, B. B.; SCHROEDER, R. G.; FLYNN, E. J.; SAKAKIBARA, S. e BATES, K. A. (1997). World-Class Manufacturing Project: Overview and Selected results. International Journal of Operations \& Productions Management, 17(7):671-685.

FORKER, L. B.; VICKERY, S. K. e DROGE, C. L. (1996). The Contribution of Quality to Business Performance. International Journal of Operations \& Productions Management, 16(8):44-62.

GABOR, A. (1990). O Homem que Descobriu a Qualidade. (1 ed.). Rio de Janeiro: Qualitymark. GARVIN, D.A. 1992. Gerenciando a Qualidade. (1 ed.). Rio de Janeiro: Qualitymark.

GREENE, W. H. (2000). Econometric Analysis. (4 ed.), Upper Saddle River: Prentice-Hall.

GOULDEN, C. e RAWLINS, L. (1995). A hybrid model for process quality costing. International Journal of Quality \& Reliability Management, 12(8):32.

HERAS, I.; DICK, G. e CASADESÚS, M. (2002). ISO 9000 Registration's Impact on Sales and Profitability. International Journal of Quality \& Reliability Management, 19(6):774-791. 
International Organization For Standardization (ISO). Disponível em: http://www.iso.org. Acesso em 20/abr/2007.

JACOBSON, R. e AAKER, D. A. (1987). The Strategic Role of Product Quality. Journal of Marketing, 51(4):31-44.

MACHOWSKI, F. e DALE, B.G. (1998). Quality Costing: An Examination of Knowledge, Attitudes and Perceptions. Quality Management Journal, 5(3):84.

MAHER, M. (2001). Contabilidade de Custos: Criando Valor para a Administração. (2 ed.). São Paulo: Atlas.

MANDEL, B. J. (1972). Quality Costing Systems. Quality Progress, 5(12):11. McNAIR, C.J. 1999. Beyond the Boundaries: Future Trends in Cost Management. Journal of Cost Management, 21(1):10-21.

MARSHALL, I. Jr.; ROCHA, A. V.; MOTA, E. B.; CIERCO, A. A. e LEUSIN, S. (2006). Gestão da Qualidade. (7 ed.). Rio de Janeiro: Editora FGV.

MERINO, D. N. (1988). Economics of Quality: Choosing among Prevention Alternatives. International Journal of Quality \& Reliability Management, September: 13.

NICOLAU, J. L. e SELLERS, R. (2002). The Stock Market's Reaction to Quality Certification: Empirical Evidence from Spain. European Journal of Operational Research, 142:632-641.

OMACHONU, V. K.; SUTHUMMANON, S. e EINSPRUCH, N. G. (2004). The Relationship between Quality and Quality Cost for a Manufacturing Company. International Journal of Quality \& Reliability Management, 21(2/3):277-290.

PHILIPS, L. W.; CHANG, D. R. e BUZER, R. D. (1983). Product Quality, Cost Position and Business Performance: A Test of some Key Hypotheses. Journal of Marketing, 47: 26-43.

RICHIERI, F. L. (2007). Capital Intelectual e a Criação de Valor nas Empresas Brasileiras. (Dissertação de Mestrado). Universidade Presbiteriana Mackenzie. São Paulo, SP.

RODRIGUES, F. C. T. S. (1996). Quality from Brazil. Revista Trevisan, 103, setembro.

RODRIGUES, F. C. T. S. (2007). A Certificação ISO 9000 e o Desempenho Financeiro das Companhias Abertas Brasileiras. (Dissertação de Mestrado). Universidade Presbiteriana Mackenzie, São Paulo, SP. 
ROTH, J. L. (1998). Impactos da ISO 9000 sobre a Gestão das Empresas: Inferências a partir de Três Estudos de Casos. (Dissertação de Mestrado). Escola de Administração. Universidade Federal do Rio Grande do Sul. Porto Alegre, RS.

RUST, R. T.; ZAHORIK, A. J. e KEININGHAM, T. I. (1994). Return on Quality (ROQ): Making Service Quality Financially Accountable. Journal of Marketing, 59(2):58- 70.

SANTOS, L. e ESCANCIANO, C. (2002). Benefits of the ISO 9000:1994 System. International Journal of Quality \& Reliability Management, 19(3):321-334.

SCHIFFAUEROVA, A. e THOMSON, V. (2006). A Review of Research on Cost of Quality Models and Best Practices. International Journal of Quality \& Reliability Management, 23(6):647-669.

SIMMONS, B. L. e WHITE, M. A. (1999). The Relationship between ISO 9000 and Business Performance: Does Registration really matters? Journal of Managerial Issues, 11(3):330-343.

SOWER, V. E.; QUARLES, R. e BROUSSARD, E. (2007). Cost of Quality Usage and Its Relationship to Quality System Maturity. International Journal of Quality \& Reliability Management, 24(2):121-140.

SZYMANSKI, D. M.; BHARADWAJ, S. G. e VARADAJAN, P. R. (1993). An Analysis of the Market Share - Profitability Relationship. Journal of Marketing, 57:1-18.

SZYSZKA, I. (2000). Implantação de Sistemas da Qualidade ISO 9000 e Mudanças Organizacionais. (Dissertação de Mestrado). Escola de Administração. Universidade Federal do Rio Grande do Sul. Porto Alegre, RS.

TERLAAK, A. e KING, A. A. (2006). The Effect of Certification with the ISO 9000 Quality Management Standard: a Signaling Approach. Journal of Economic Behavior and Organization, 60(4):579-602.

TIROLE, J. (1990). The Theory of Industrial Organization. Cambridge: MIT Press.

VIGER, C. e ANANDARAJAN, A. (1999). Cost Management and Pricing Decisions in the Presence of Quality Cost Information: An Experimental Study with Marketing Managers. Journal of Cost Management, 13(1):21-28.

WANG, G.; GAO, Z. e LIN, T. (2007). Integrating the Quality Cost Report and TQM Tools to Achieve Competitive Advantage. Journal of Cost Management, 21(1):42- 47.

WOOLDRIDGE, J. M. (2006). Introdução à Econometria: Uma Abordagem Moderna. (1 ed.), São Paulo: Thomson. 
Os Custos da Qualidade e a Certificação ISO 9000: Um Estudo com Dados em Painel de

Companhias Abertas Brasileiras

Francisco Carlos Tadeu Starke Rodrigues, Laércio Baptista da Silva, Wilson Toshiro Nakamura, Diógenes Manoel Leiva Martin

Data de Submissão: 02/12/2008

Data de Aceite: 16/12/2008 